\title{
Rectal Cancer and Invasion of Veins: Importance in TNM Staging 2
}

\author{
Kiss Lorant* Kiss Roland and Milcioiu Denisa
}

I-rst Surgical Clinic, Emergency Academic Hospital Sibiu, Lucian Blaga, University of Sibiu, Romania

\begin{abstract}
Summary: Accurate information about infiltration of the tumor to the various layers of the rectal wall is important.

Material and methods: A histopathological study of surgical specimens from 351 surgical specimens from patients with adenocarcinoma of the rectum revealed invasion of veins by primary growth in almost $52 \%$.

Results: Follow-up studies showed that the corrected 5-year survival rate was significantly worse and liver metastases developed more frequently when venous invasion was present.

Invasion of extramural veins was particularly significant whereas spread confined to intramural veins was less important. Invasion of large (thick-walled) veins was of greater consequence than invasion of small (thin-walled) veins and spread into thick-walled extramural veins, had greatest adverse influence of all.

Venous spread of tumor takes place in parallel with local spread as measured by the Dukes' stage but exerts an influence on prognosis independent of the Dukes' stage.

Similarly, veins invasion parallels the number of lymph nodes metastases but appears to exert an independent influence on prognosis.

Conclusion: The venous spread provides a precise assessment of the likely behavior of rectal cancer, but does not replace indices such as the Dukes' stage, or the number of lymph nodes metastases in use.
\end{abstract}

Keywords: Dukes's stage; Rectal cancer; Vein invasion

\section{Introduction}

Once a diagnosis of rectal cancer has been confirmed histologically, preoperative staging is mandatory to assist therapeutic decision making $[1]$.

Today, several imaging modalities of great potential exist for local staging, including three-dimensional reconstruction [2-4]. The value of these techniques has been expressed as a correlation between the pretreatment tumor stage (CT) and the corresponding pathological stage (PT), the latter being regarded as the "gold standard".

Accurate information about infiltration of the tumor to the various layers of the rectal wall is important if local excision is anticipated [5]. The best modality with an acceptable accuracy for determining invasion into the layers of the bowel wall is end rectal ultrasonography [2].

Since the initial report by Brown and Warren in 1938 demonstrating an increase in visceral metastases on patients with rectal cancer with vascular invasion, a number of investigators have examined the influence of vascular invasion by tumor in colorectal cancer. They are two type of vascular invasion: blood vessel and lymphatic vessel invasion [5]. One would predict the presence of vascular invasion to be associated with an increased incidence of lymph nodes metastases and distant dissemination and with a decrease in survival [6].

Differences in the definition of vascular invasion, the methods of detection, and perhaps, the metastatic potential of the cells once they have gained access to blood and lymphatic vessels may explain, in part, some of the variations observed [7].

Surgical removal of the rectum by either synchronous combined excision or anterior resection with TME or Partial Mezorectum Excision (PME).

In an autopsy review they found that visceral metastases developed in two-thirds of cases in which there was venous invasion, but in no case in which venous invasion was not seen. In some studies the presence of carcinoma cells was found in the peripheral blood in 8 of 15 cases with histological evidence of venous invasion in the surgically excised specimens of rectum.

In other studies the authors suggest that invasion of veins may occur without being histologically demonstrable [8]

An important issue raised by Quirke and Morris is the recommendation to use the fifth rather than the sixth edition of TNM When dealing with venous invasion and tumor nodules/deposits in the pericolorectal adipose tissue of a primary carcinoma, without histological evidence of residual lymph node [9].

Compared the staging methods, the Astler-Coller stage and the presence or absence of BW (blood vessel invasion) is the most significant correlation with survival, in patients with lymph node metastases [10].

\section{Patients and Methods}

The histological sections from 351 operation specimens from patients operated on for cure of carcinoma of the rectum between 1992-2007 were reviewed giving particular attention to the presence and extent of any invasion of veins: invasion of veins outside the

*Corresponding author: Kiss Lorant, Emergency Academic Hospital, Sibiu Lucian Blaga, University of Sibiu, Sibiu, Romania, Tel: 40269215; E-mail: drkisslorant@yahoo.com

Received July 20, 2015; Accepted December 20, 2015; Published February 10 2016

Citation: Lorant K, Roland K, Denisa M (2016) Rectal Cancer and Invasion of Veins: Importance in TNM Staging 2. J Blood Lymph 6: 144. doi: 10.4172/21657831.1000144

Copyright: $\odot 2016$ Lorant $\mathrm{K}$, et al. This is an open-access article distributed unde the terms of the Creative Commons Attribution License, which permits unrestricted use, distribution, and reproduction in any medium, provided the original author and source are credited. 
muscle of the rectal wall was classified as extramural venous spread, while invasion of veins in the submucoasa or muscular is propria only was classified as intramural venous spread. The thickness of the wall of any invaded vein was also voted: veins with thick walls containing a well-developed smooth muscle layer were classified as "thick-walled", whereas veins which were more sinusoid in nature with thin walls containing little or no muscle were classified as "thin-walled".

The Dukes' stage and the number of lymph nodes that contained metastases were also recorded in each case.

Because of the large volume of histological and clinical data, the information was transferred into computer punch cards for analysis (SPSS-Chicago). The statistical significance of results was assessed using the $\mathrm{x}^{2}$ test.

\section{Results}

Of the patients who died the cause of death was confirmed by autopsy in only 17 cases, but liver metastases were found at primary operation or at subsequent laparotomy in 44 cases.

Liver metastases were assumed in 27 patients who had clinically enlarged knobbly liver and in a further 7 patients with a history of weight loss with jaundice before death.

\section{Incidence of venous invasion}

Evidence of invasion of rectal veins by tumor was found in 182 of the 351 cases $(51.9 \%)$, fully studied and, as Table 1 shows, in over twothirds of these extramural veins were involved (127 36.0 \%) (Table 1).

\section{Venous invasion and Dukes' staging}

The incidence of venous invasion increased with the Dukes' stage $20 \%$ in stage A, $47 \%$ in stage B and $64 \%$ in stage C (Table 2).

Of the 9 stage A lesions in which venous spread was demonstrated only $1(5 \%)$ involved extramural veins.

In contrast, when tumor had breached the bowel wale the incidence of extramural venous invasion was higher and was not influenced by lymph node status ( $70 \%$ and $75 \%$ for stage $\mathrm{B}$ and $\mathrm{C}$ respectively).

\section{Liver metastases and venous invasion}

Liver metastases and death have an overall incidence 25\% (Table $3)$.

A low incidence of liver metastases was observed in patients in whom venous invasion was not demonstrated, in comparation with patients in whom venous invasion had occurred (14\% and $35 \%$ respectively, $\mathrm{p}<0.001)$.

In the latter group, liver dissemination were less common in preserve of venous invasion to the rectal wall (intramural), compared with extramural venous spread ( $23 \%$ and $40 \%$ respectively).

The type of extramural venous invasion and liver metastases is show in Table 4.

Liver metastases were present in $57 \%$ of cases in which thickwalled extramural veins dissemination was present $(p<0.001)$.

\section{The survival in 351 patients}

The overall 5 year survival rate of the 351 patients was $57 \%$. From this survival rate are excluded all patients who died in the immediate preoperative period of 4 weeks (Table 5).
In cases that the venous invasion was not demonstrated, the corrected 5 year survival rate was $73 \%$.

The survival rate when venous invasion was combined to the bowel wall $(66 \%)$ did not differ significantly from when venous invasion was not demonstrated $(0.2<\mathrm{p}<0.5)$, but in presence of extramural venous invasion the corrected 5-year survival rate was halved to $33 \%(\mathrm{p}<0.001)$

Table 4 shows the type of extramural venous invasion and survival rate. In this table, the corrected 5-year survival rate in presence of invaded extramural veins with thick-walled vessels was only $19 \%$, less than half then thin-walled extramural veins were involved $(\mathrm{p}<0.001)$ (Table 6).

The combined effect on the corrected survival rate of the venous invasion and the Dukes' invasion had no significant effect on survival in stage A category cases, but the presence of extramural venous invasion is associated a decrease in survival in $B$ and $C$ stage growths. The special situation was observed in stage $\mathrm{C}$ category, in these cases the presence of thick-walled extramural veins invasion was associated with only $8 \%$ survival, but even in the presence of the extramural veins invasion only

\begin{tabular}{|c|c|c|}
\hline Venous invasion & No & $\%$ \\
\hline Not present & 169 & 41.1 \\
\hline Present & 182 & 51.9 \\
\hline -Intramural & 55 & 15.8 \\
\hline -Extramural & 127 & 36 \\
\hline Total & 351 & 100 \\
\hline
\end{tabular}

Table 1: Venos invasion in surgical specimens of rectal cancer.

\begin{tabular}{|c|c|c|c|}
\hline \multirow{2}{*}{ Dukes' stage } & Present \% & Intramural only & Extramural only \\
\cline { 2 - 4 } & & $\mathbf{N} / \%$ & $\mathbf{N} / \%$ \\
\hline$A$ & 9 & 9 & 1 \\
\hline$(n=47)$ & -20 & -95 & -5 \\
\hline$B$ & 62 & 18 & 44 \\
\hline$(n=132)$ & -47 & -40 & -70 \\
\hline C & 110 & 26 & 83 \\
\hline$(n=171)$ & -64 & -25 & -75 \\
\hline
\end{tabular}

Table 2: Dukes' stage, venous invasion of rectum carcinoma

\begin{tabular}{|c|c|c|c|}
\hline Venous invasion & Total & Number with liver metastases & $\%$ \\
\hline Not demonstrated & 169 & 24 & 14.2 \\
\hline Present & & & \\
\hline -Intramural & 55 & 13 & 23.4 \\
\hline -Extramural & 127 & 51 & 40.2 \\
\hline All cases & 351 & 88 & 25 \\
\hline
\end{tabular}

Table 3: Liver metastases in rectal cancer patients, and venous invasion.

\begin{tabular}{|c|c|c|c|}
\hline Invaded extramural veins & Total & Number with liver metastases & $\mathbf{\%}$ \\
\hline Thin-walled & 80 & 24 & 30.4 \\
\hline Thick-walled & 47 & 26 & 57 \\
\hline
\end{tabular}

Table 4: Extramural venous invasion and liver metastases.

\begin{tabular}{|l|c|cc|c|}
\hline Venous invasion & \multicolumn{3}{|c|}{} \\
\hline & $\begin{array}{c}\text { Not } \\
\text { demosntrated }\end{array}$ & \multicolumn{2}{|c|}{ Present } & \multirow{2}{*}{ Total } \\
\cline { 1 - 4 } & Intra/Extra & \\
\hline Patients survivors after first 4 weeks & 164 & 54 & 124 & 342 \\
\hline 5-year survival & 103 & 30 & 35 & 168 \\
\hline Corrected 5 year survival rate (\%) & 73 & 60 & 33 & 57 \\
\hline
\end{tabular}

Table 5: Patients with rectal cancer, and survival rate; and venous invasion. 


\begin{tabular}{|c|c|c|c|}
\hline $\begin{array}{c}\text { Invaded extramural } \\
\text { veins }\end{array}$ & $\begin{array}{c}\text { Survivors after } \\
\text { surgery }\end{array}$ & 5-year survivors & $\begin{array}{c}\text { Corrected } \\
\text { 5-year \% }\end{array}$ \\
\hline Thin-walled & 78 & 28 & 41 \\
\hline Thick-walled & 45 & 8 & 19 \\
\hline
\end{tabular}

Table 6: The extramural venous invasion and survival rate.

\begin{tabular}{|c|c|c|c|}
\hline \multirow{2}{*}{ Venous invasion } & \multicolumn{3}{|c|}{ Dukes' stage and 5 year survival rate \% } \\
\cline { 2 - 4 } & A & B & C \\
\hline Not demonstrated & 48 & 43 & 23 \\
\hline Present & & & \\
\hline -Intramural & 51 & 42 & 20 \\
\hline -Extramural & & & \\
\hline Thin-walled & - & 68 & 23 \\
\hline Thick-walled & 0 & 52 & 8 \\
\hline Total & $96 \%$ & $78 \%$ & $31 \%$ \\
\hline
\end{tabular}

Table 7: Survival rate, venous invasion Dukes' stage.

\begin{tabular}{|c|c|c|c|c|}
\hline Number & $\begin{array}{c}\text { Survival after } \\
\text { surgery }\end{array}$ & $\begin{array}{c}\text { Nr. of 5 years } \\
\text { survivors }\end{array}$ & $\begin{array}{c}\text { Corected } \\
\text { 5-year survival } \\
\text { rate (\%) }\end{array}$ & p. \\
\hline $\begin{array}{c}\text { 1-3 lymph node } \\
\text { (NL) metastases }\end{array}$ & & & & \\
\hline Not demonstrated & 38 & 20 & 29 & $<0.05$ \\
\hline Intramural & 17 & 5 & 20 & 0.2 \\
\hline Extramural & 35 & 9 & 15 & $<0.001$ \\
\hline Total & 90 & $68 \%$ & $43 \%$ & \\
\hline $\mathbf{2}$ N NL metastases & & & & \\
\hline Not demonstrated & 21 & 4 & 12 & $<0.02$ \\
\hline Intramural & 9 & 3 & 21 & 0.1 \\
\hline Extramural & 43 & 3 & 4 & $<0.001$ \\
\hline Total & 73 & $22 \%$ & $17 \%$ & $<0.001$ \\
\hline
\end{tabular}

Table 8: Survival rate, lymph node metastases, and venous invasion.

in the thin-walled vessels the survival rate was halved in comparation with when venous invasion was not demonstrated (Table 7).

In Dukes' tumors the corrected 5-year survival rate is less than $43 \%$ when less than four lymph node metastases were present (Table 8).

In this group (stage C) of cases with few lymph node metastases, the 5-year survival rate was considerably higher (59\%) when venous invasion was not present. In presence of extramural or intramural dissemination in veins the corrected survival rate was lower of $30 \%$.

In presence of four or more lymph modes metastases the corrected 5 -year survival rate was $17 \%$ and in presence of extramural venous dissemination in these cases the survival rate was $8 \%$.

\section{Discussion}

Horn et al. found that Blood Vessel Invasion (BVI) was an independent prognostic factor for distant metastases but not for survival [5].

The presence of venous invasion in associated with an increased risk of the future development of distant metastases (particularly hepatic) and cancer-related death [11-14].

Since the 1990s, several authors have investigated the clinical implications of extramural tumor deposits with no residual LN structure in colorectal cancer $[15,16]$.

In same studies two types of BVI are described. Invasion of blood vessels within the bowel wall is defines as intramural BVI and invasion of blood vessels outside the bowel wall (per colonic fat or subserosal fat) is defined as extramural BVI invasion [17-19]. Both Talbot et al. [9] and Minsky et al. [6] found that the extramural component of blood vessel invasion was not predictive of survival.

The observation of BVI in $51.9 \%$ of cases of carcinoma of the rectum is a rather higher incidence than previously reported from others.

The result from the present study indicates that there is a significantly lower survival rate when venous invasion and venous spread is observed. This is evidently because tumor spread by the blood stream is a consequence of venous invasion [19-22]. Liver metastases developed over twice as frequently in patients with venous invasion as in those in whom it was not demonstrated.

Dissemination into extramural veins for a more pronounced effect of on liver metastases formation and survival rate than invasion of intramural veins only [23-24]. The difference between intramural venous invasion and not demonstrable VNI with regard to liver metastases and to 5-year survival is not statistically significant [2527]. Some studies shown that when such invaded thick-walled veins lie outside the rectal wall there is particularity poor prognoses [28-30].

The present study suggests that the correlation of extend of VNI and the Dukes' stage shown that local spread proceeds in parallel with venous invasion, but venous spread (Table 7) exerts an influence in progress independent of the Dukes' stage.

Correction studies on the presence or absence of lymph node metastases based on imaging report a low predictive value. However, the question remains of how important this is, as there are only two circumstances is which the presence of lymph node metastases is relevant in clinical decision making: first, the choice of local excision in the absence of lymphadenopathy and second the present of lymph node metastases outside the end pelvic envelope makes the primary tumor locally advanced [31-33]. In this first situation the histological characteristics of the primary tumor are now relevant than lymph node imaging [34-36].

The results of this study provide such an indication by demonstrating that venous dissemination of rectal cancer is directly related to the development of liver metastases, and this observation is in concordance with other publications [37-39]. Our results demonstrate that the spread of cancer of the rectum into veins is of the greatest importance in the natural history of the disease, possibly more important than lymphatic spread.

The Dukes' staging is a remarkably consistent index of prognosis, for a minimal amount of extra attention to histological details its usefulness, still further increased.

The presence of VNI in Dukes' classification with extramural veins invasion significantly reduce the 5 -year survival rate of stage $B$ and $\mathrm{C}$ cases, and when thick-walled extramural veins are invaded the prognosis is particularly poor.

The importance of venous spread carries implication for surgical technique in the treatment of rectal cancer and provides a rational basis for early ligation of the superior hemorroidal vein, as advocated by Moynihan.

Our results lend weight to the theoretical considerations by showing that veins are invaded by tumor in over $50 \%$ of cases of rectal cancer and malignant emboli are likely to be released by operative manipulation in these cases [40-42]. 
Preoperative chemo radiotherapy (CRT) is used in the management of locally advanced rectal cancer to downsize tumor bulk and reduce the risk of local pelvic recurrence [43-45].

In some studies, $35 \%$ of patients had a complete pathologic response after neoadjuvant CRT. More than 3\% of patients are metastatic disease within the mesorectal lymph node despite achieving PCR of the primary tumor [46-49].

In our study, the rate of metastatic deposits within nodes increased proportionally with $\mathrm{T}$ stage.

Quirke and Morris published in Histopathology [28], about the guidelines for the reporting of surgically resected specimens of colorectal cancer [9]. The authors state that 15-18 LM are usually recovered in the best centers and this number is advisable for all pathologists [1]. However, there is no general consensus given that other authors, reporting colorectal cover guidelines, have recently proposed a mean number of 12-15 LNs [50].

In a large series of colorectal cancers reported by Goldstein, about $30 \%$ of pT3N+ patients had a single metastatic lymph node (LN) and the percentage of specimens with one LN metastases increased from $41.62 \%$ to $80.36 \%$ when the number of LNs increased from $11-15$ to $>21 \mathrm{LN}$.

\section{Conclusions}

Observation of venous spread provides a precise assessment of the likely behavior of rectal carcinoma, but does not replace the Dukes' stage, TNM and/or the number of lymph nodes metastases in routine use.

\section{References}

1. Starck M, Bohe M, Fork FT, Lindstrom C, Sjoberg S, et al. (1995) Endoluminal ultrasound and low-field magnetic resonance imaging are superior to clinical examination in the preoperative staging of rectal cancer. Eur J Surg 161: 841 845.

2. Mackay SG, Pager CK, Joseph D, Stewart PJ, Solomon MJ, et al. (2003) Assessment of the accuracy of transrectal ultrasonography in anorectal neoplasia. Br J Surg 90: 346-350.

3. Matsuoka H, Nakamura A, Masaki T, Sugiyama M, Takahara T, et al. (2002) Preoperative staging by multidetector-row computed tomography in patients with rectal carcinoma. Am J Surg 184: 131-135.

4. Brown G, Radcliffe AG, Newcombe RG, Dallimore NS, Bourne MW, et al. (2003) Preoperative assessment of prognostic factors in rectal cancer using high-resolution magnetic resonance imaging. Br J Surg 90: 355-364.

5. Garcia-Aquilar J, Mellgren A, Sirivongs P, Buie D, Madoff RD, et al. (2000) Local excision of rectal cancer without adjuvant theraphy: a word of caution. Ann Surg 231: 345-351.

6. Minsky BD, Mies C (1989) The clinical significance of vascular invasion in colorectal cancer. Dis colon Rectum 32: 794-803.

7. Krasna MJ, Flancbaum L, Cody RP, Schneibaum S, Ben AG, et al. (1988) Vascular and neural invasion in colorectal carcinoma. Incidence and prognostic significance. Cancer 61: 1018-1023.

8. Schirouzu K, Isomoto H, Kakegawa T, Morimatsu M (1991) A prospective clinicopathologic study of venous invasion in colorectal cancer. Am J Sung 162: 216-220.

9. Inoue T, Mori M, Shimono R, Kuwano H, Sugimatchi K, et al. (1992) Vascular invasion of colorectal carcinoma readily visible with certain stains. Dis Colon Rectum 35: 34-39.

10. Jen j, Kim H, Piantadosi S, Liu ZF, Levitt RC, et al. (1994) Allelic loss of chromosome 18q and prognosis in colorectal cancer. N Engh J Med 331: 213221

11. Krasna MJ, Flanbaum L, Cody RP, Shneibaumet S, Ari GB, et al. (1988) Vascular and neural invasion in colorectal carcinoma. Cancer 61: 1018-1023.
12. Horn A, Dahl O, Morild I (1991) Venous and neural invasion as predictors of recurrence in rectal adenocarcinoma. Dis Colon Rectum 34: 798-804.

13. Ouchi K, Sugawara T, Ono H, Fujiya T, Kamiyama Y, et al. (1996) Histologic features and clinical significance of venous invasion in colorectal carcinoma with hepatic metastasis. Cancer 78: 2313-2317.

14. Birgisson G, Pahlman L, Gunnarsson U, Glimelius B (2005) Occurrence of second cancers in patients treated with radiotherapy for rectal cancer. J Clin Oncol 23: 6126-6131.

15. Folkesson J, Birgisson H, Pahlman L, Cedermark B, Glimelius B, et al. (2005) Swedish rectal cancer trial: Long lasting benefits from radiotherapy on survival and local recurrence rate. J Clin Oncol 23: 5644-5650.

16. Nagtegaal ID, Van de Velde CJ, van der Worp E, Kapiteijn E, Quirke P, et al (2002) Macroscopic evaluation of rectal cancer resection specimen: Clinical significance of the pathologist in quality control. J Clin Oncol 20: 1729-1734.

17. West NP, Finan PJ, Anderin C, Lindholm J, Holm T, et al. (2008) Evidence of the oncologic superiority of cylindrical abdominoperineal excizion for low rectal cancer. J Clin Oncol 26: 3517-3522.

18. Kim YW, Kim NK, Min BS, Lee KY, Sohn SK, et al. (2009) The prognostic impact of the number of lymph nodes retrieved after neoadjuvant chemoradiotherapy with mesorectal excision for rectal cancer. J Surg Oncol 100: 1-7.

19. Borschitz T, Wachtlin D, Mohler M, Schmidberger H, Junginger T, et al. (2008) Neoadjuvant chemoradiation and local excision for T2-3 rectal cancer. Ann Surg Oncol 15: 712-720.

20. Ota DM, Nelson H, ACOSOG protocol Group Co-Chairs (2007) Local excision of rectal cancer revisited: ACOSOG Protocol Z6041. Annals of Surgical Oncology 14: 271

21. Washington MK (2008) Colorectal carcinoma: selected issues in pathologic examination and staging and determination of prognostic factors. Arch Pathol Lab Med 132: 1600-1607.

22. Eon Y, Douy JY, lamer B, Battini J, Bretagne JF (2006) Quality and completeness of histopathology reports of rectal cancer resection. Result of an adult in Brittany. Gastroenterol Clin Biol 30: 235-240.

23. Jass JR, O'Brien j, Riddell RH, Snover DC (2008) Recommendations for the reporting of surgically resected specimens of colorectal carcinoma: association of directors of anatomic and surgical pathology. Am J Clin Pathol 129: 13-23.

24. DAP-TM-30 (2007) Leitfadenzur Interpretation der Anforderungen der DIN EN ISO/IEC 17020: 2004 und technische Kriterien fuer deren Anwendung zur Akkreditierung in der Pathologie/Neuropathologie.

25. Risio M, Bussolati G, Senore C, Vigna S, Frangipane E, et al. (2010) Virtua microscopy for histology quality assurance of screen-detected polyps. J Clin Pathol 63: 916-920.

26. Greene FL, Sobin LH (2009) A worldwide approach to the TNM staging system: collaborative efforts of the AJCC and UICC. Journal of Surgical Oncology 99 269-272.

27. Edge Sb, Byrd Dr, Compton CC, Fritz, AG, Greene, FL, et al. AJCC Cancer Staging manual ( $7^{\text {th }}$ edn.). Springer Verlag, New York, 2010.

28. Nagtegaal ID, Quirke P (2007) Colorectal tumor deposits in the mesorectum and pericolon: a critical review. Histopathology 51: 141-149.

29. Nagtegaal ID, Tot T, Jayne Dg, McShane P, Nihlberg A, et al. (2011) Lymph nodes, tumor deposits, and TNM: are we getting better? J Clin Oncol 29: 2487 2492

30. Simunovic M, Sexton R, Rempel E, moran BJ, Heald RJ, et al. (2003) Optimal preoperative assessment and surgery for rectal cancer greatly limit the need for radiotherapy. Br J Surg 90: 999-1003.

31. Lezoche E, Guerrieri M, Paganini AM, Feliciotti F (2002) Long-term results of patients with pT2 rectal cancer treated with radiotherapy and transanal endoscopic microsurgical excision. World J Surg 26: 1170-1174.

32. Zmora O, Dasilva GM, Gurland B, Pfeffer R, Koller M, et al. (2004) Does recta wall tumor eradication with preoperative chemoradiation permit a change in the oparative strategy? Dis Colon Rectum 47: 1607-1612.

33. West NP, Finan PJ, Anderin C, Lingholm J, Holm T, et al. (2008) Evidence of the oncologic superiority of cylindrical abdominoperineal excision for low rectal cancer. J Clin Onco 26: 3517-3522. 
Citation: Lorant K, Roland K, Denisa M (2016) Rectal Cancer and Invasion of Veins: Importance in TNM Staging 2. J Blood Lymph 6: 144. doi: 10.4172/2165-7831.1000144

Page 5 of 5

34. Quincke P, Steele R, Monson J, Grieve R, Khanna S, et al. (2009) Effect of the plane of surgery archieved on local recurrence in patients with operable rectal cancer: a prospective study using data from the MRC CR07 and NCIC-CTG C016 randomised clinical trial. Lancet 373: 821-828.

35. Valentini V, Glimelius B, Aristei C, Minsky BD, Beets-Tan R, et al. (2009) Multidisciplinary rectal cancer management: $2^{\text {nd }}$ European Rectal Cancer Consensus Conference (EURECA-CC2). Radiother Oncol 92: 148-163.

36. Hiotis SP, Weber SM, Cohen AM, Minsky BD, Paty PB, et al. (2002) Assessing the predictive value of clinical complete response to neoadjuvant therapy for rectal cancer: an analysis of 488 patients. J Am Coll Surg 194: 131-135.

37. Habr-Gama A, Perez Ro, Nadalin W, Sabbaga J, Ribeiro U Jr, et al. (2004) Operative versus nonoperative treatment for stage 0 distal rectal cance following chemoradiation therapy: long-therm result. Ann Surg 240: 711-717.

38. You YN, Baxter NN, Stewart A, Nelson H (2007) Is the increasing rate of local excision for stage I rectal cancer in the United States justified? A nationwide cohort study from the National Cancer Database. Ann Surg 245: 726-733.

39. Jorgen F, Johansson R, Damber L, landmark G (2010) Risk factors of recta cancer local recurrence: population-based survey and validation of the Swedish Rectal Cancer registry. Colorectal Dis 12: 977-986.

40. Radu C, Berglund A, Pahlman L, Glimelius B (2008) Short-course preoperative radiotherapy with delayed surgery in rectal cancer - a retrospective study. Radiother Oncol 87: 343-349.

41. Pettersson D, Cedermark B, Holm T, Radu C, Påhlman L, et al. (2010) Interim analysis of the Stockholm III trial of preoperative radiotherapy regimens for rectal cancer. Br J Surg 97: 580-587.

42. Anonymous (1997) Improved survival with preoperative radiotheraphy in resectable rectal cancer. Swedish Rectal Cancer Trial. N Engl J Med 336: 980987
43. Kapitejin E, Marijnen CAM, Nagtegaal ID, Putter H, Steup WH, et al. (2001) Preoperative radiotherapy conbined with total mesorectal excision for respectable rectal cancer. N Engl J Med 345: 638-646.

44. Perez Ro, Habr-Gama A, Proscurshim I, Campos FG, Kiss D, et al. (2007) Loca excision for ypT2 rectal cancer-much ado about something. J Gastrointest Surg 11: $1431-1440$.

45. Medich D, McGinty J, Parda D, Karlovits S, Davis C, et al (2001) Preoperative chemoradiotherapy and radical surgery for locally advanced distal rectal adenocarcinoma: pathologic findings and clinical implications. Dis Colon Rectum 44: 1123-1128.

46. Read TE, Andujar JE, Caushaj PF, Douglas RJ, David WD, et al. (2004) Neoadjuvant theraphy for rectal cancer: histologic response of the primary tumor predicts nodal status. Diseases of the Colon \& Rectum 47: 825-831.

47. Stipa F, Zernecke A, Moore HG, Minsky BD, Wong WD, et al. (2004) Residual mesorectal lymph node involvement following neoadjuvant combined-modality therapy: rationale for radical resection? Ann Surg Oncol 11: 187-191.

48. Bedrosian I, Rodriguez-Bigas MA, Feig B, Hunt KK, Ellis L, et al. (2004) Predicting the node-negative mesorectum after preoperative chemoradiation for locally advanced rectal carcinoma. J Gastrointest Surg 8: 56-62.

49. Jass JR, o'Brien MJ, Riddell RH, Snover DC (2007) Recommendation for the reporting of surgically resected specimens of colorectal carcinoma. Virchow Arch 450: 1-13.

50. Goldstein NS (2002) Lymph node recoveries from 2427 pT3 colorecta resection specimens spanning 45 years: recommendations for a minimum number of recovered lymph nodes based on predictive probabilities. Am J Surg Pathol 26: 179-189. 